\title{
Medium Chain Triglycerides Reduces Levels of Aß-42 in Sprague Dawley with Cognitive Function Impairment
}

\author{
Faradila ${ }^{1}$, Nur Indrawaty Liputo ${ }^{2}$ \\ \{faradila1991@hotmail.com ${ }^{1}$, indra.liputo@gmail.com ${ }^{2}$ \} \\ Faculty of Medicine, Universitas Andalas, Padang, Indonesia
}

\begin{abstract}
This study aims to find how Medium Chain Triglycerides (MCT) effect on biological markers of Alzheimer's disease, Amyloid-beta 42 (A $\beta-42)$. The amyloid cascade hypothesis is the main hypothesis of the pathogenesis of Alzheimer's disease. This hypothesis explains that senile plaque which containing Amyloid-beta is neurotoxic and causing brain metabolism disorders. In Alzheimer's disease, brain cells also lose their ability to use glucose as fuel, whereas glucose is the main energy source for brain metabolism. Medium Chain Triglycerides (MCT) consumption is expected to provide substitute energy for glucose after being metabolized by the liver to a ketone body, which is then released into the bloodstream to provide alternative energy sources as an energy source for the brain's metabolism to prevent the cognitive function from worsening. This study was an experimental study with post test only control group design and was performed on 24 induce rats (Sprague Dawley) divided into 4 groups, positive control, negative control, dose $1 \mathrm{MCT}$ and dosed $2 \mathrm{MCT}$. Rats were treated with daily consumption of MCT during 4 weeks, then $\mathrm{A} \beta-42$ levels were examined in rats CSF using ELISA method. The negative and positive control groups showed significantly higher A $\beta-42$ levels with groups taking MCT.
\end{abstract}

Keywords: Alzheimer's Disease, Amyloid-beta 42, Medium Chain Triglycerides.

\section{Introduction}

Alzheimer's disease $(\mathrm{AD})$ is the most common neurodegenerative disease in the world, affecting approximately more than $50 \%$ of people between the ages of 75 to 84 years [1]. The main symptoms of Alzheimer's disease are progressive impairment in memory and language and are accompanied by time and place disorientation, visualuopathic disorders, impaired calculations ability, and the worst can cause personality disorders and behavioral changes [2]. Pathologically, Alzheimer's Disease is characterized by the accumulation of senile plaques and neurofibrillary tangles. The plaques contain large amounts of the amyloid-beta (A $\beta$ ) peptide derived from cleavage of the amyloid precursor protein (APP) [3].

The amyloid cascade hypothesis is the main hypothesis of the pathogenesis of Alzheimer's disease. This hypothesis explains that the formation of senile plaques is composed of Amyloidbeta peptides. The formation of senile plaques is considered to be the cause of cognitive function decline [4]. The development of Alzheimer's Disease and the accumulation of A $\beta$ have been linked to dietary factors. The brain is a glucose-dependent organ. The recent studies show that most of the glucose consumed by the brain is used to maintain the resting potential of neurons. 
The Alzheimer's patients commonly develop glucose intolerance, which may progress to abnormal brain glucose metabolism. This is thought to be influenced by an increase in senile plaque density [2],[5].

Disorders of brain glucose metabolism can worsen cognitive function, so alternative glucose substitutes are needed to maintain brain metabolism normally. However, it takes a material whose metabolism is similar to glucose and can pass through the blood-brain barrier [6]. Medium Chain Triglycerides (MCT) is a material whose metabolism in some ways is similar to glucose metabolism because it together produces fast energy. In addition, MCT metabolism produces ketone bodies, which are compounds other than glucose that can be used by the brain as an energy source and can be through the blood-brain barrier [7,8]. The brain is capable of converting ketones to ATP through all the necessary steps, including conversion of $\beta$ hydroxybutyrate to acetoacetate, acetoacetate to acetoacetyl CoA, and acetoacetyl CoA to acetyl CoA [5],[8].

MCT consists of fatty acids with a chain length of 6-12 carbon atoms and is most commonly contained in coconut oil and palm oil. MCT does not enter the lymphatic system and peripheral circulation as chylomicrons but is directly transported to the liver through the portal circulation, thus affecting the speed of metabolism to energy [9]. Intraluminal absorption of MCT is faster and more efficient than Long Chain Triglycerides (LCT). This is because MCT can be carried out as cell fuel because it does not need to use carnitine as a means of transporting cells like other types of fat so that the energy produced is faster and more efficient [10].

\section{Method}

This research is an experimental laboratory study with a post test only control group design. Samples from this study were 24 Sprague Dawley rats induced by D-galactose and ovariectomy for 4 weeks to experience condition like Alzheimer's disease.

Furthermore, MCT was given daily. The subjects were divided into 4 groups: MCT 1, MCT 2 , positive control and negative control. The treatment was given for 4 weeks after the treatment was complete the $A \beta-42$ level was examined on cerebrospinal fluid (CSF) by ELISA method using the ELISA kit (e-EL-R 1402).

Table 1. Description of the research subject.

\begin{tabular}{lll}
\hline \multicolumn{1}{c}{ Group } & Treatment & Number \\
\hline Control negative $(\mathrm{K}-)$ & Normal rat + aquades $1 \mathrm{ml}$ & 6 rats \\
Control positive $(\mathrm{K}+)$ & Induce rat + aquades $1 \mathrm{ml}$ & 6 rats \\
MCT 1 & Induce rat + MCT 0.27 gr & 6 rats \\
MCT 2 & Induce rat + MCT 0.54 gr & 6 rats \\
\hline
\end{tabular}

The MCT dose that is often used for treatment is 15-30 gr/day. Dosage determination for rats was obtained by converting a dose of $70 \mathrm{~kg}$ human to mice with a weight of $200 \mathrm{gr}$. The conversion rate of humans to mice is 0.018 . In this study MCT doses were given in 2 dose : dose $\mathrm{I}=0.018 \times 15 \mathrm{gr}=0.27 \mathrm{gr} / \mathrm{day} / 200 \mathrm{gr}$ body weight and dose $\mathrm{II}=0.018 \times 30 \mathrm{gr}=0.54 \mathrm{gr} /$ day / 200 gr body weight $[10,11]$. 
The study was conducted at the Animal Facility \& Modeling Provider Laboratory, Bogor in June-October 2017. Twenty four female Sprague Dawley rats were fed ad libitum on a standard diet. The animals are divided into four groups, and three of them will be induced by ovariectomy and d-galactose for 4 weeks to experience Alzheimer's. After the Alzheimer's induction stage was complete, two groups were given MCT at different doses. The inclusion criteria were 12-week-old female Sprague Dawley rats weighing 200-250 grams which had suffered cognitive impairment. Exclusion criteria were those who experienced physical disabilities and died during the study.

Determination of the number of samples based on the formula Frederer $(t-1)(n-1)>15, t=$ number of treatments; $n=$ number of repetitions [12]. In this study the number of groups $(t)$ was 4 groups, so the number of repetitions of experimental animals in each group (n) was obtained as follows:

(4-1) $(n-1)>15->3(n-1)>15->3 n-3>15->3 n>18->6$.

So the number of samples in this study is $4 \times 6$ rats $=24$ rats.

After the treatment stage was complete, cerebrospinal fluid (CSF) samples are collected. Before the CSF collecting from the cysterna magna was carried out, the rats were fasted 12 hours before surgery. Anesthesia was carried out with ketamine $(100 \mathrm{mg} / \mathrm{kgBB})$ and xylazine $(10 \mathrm{mg} / \mathrm{kgBB})$ which was given intraperitoneally. During the anesthesia process, the rats are placed in the incubator at $37^{\circ} \mathrm{C}$. Then the surgical process is carried out until the duramater appears in the cysterna magna where around it appears the medulla oblongata and major blood vessels (dorsal spinal artery) and CSF cavity. Penetrate using a capillary tube to the cysterna magna through duramater. Insertion of the capillary tube results in a change in pressure so that the CSF flows into the tube. The CSF was then transferred into a $0.5 \mathrm{cc}$ appendorf tube, and the tube was immediately frozen using dry ice and stored in a freezer at $-80^{\circ} \mathrm{C}$. CFS was used for analyzing $A \beta-42$ levels using the $A \beta-42$ ELISA High Sensitivity Kit.

Descriptive analysis is done as a basis for hypothesis testing (analytical statistics). This process aims to determine the characteristics of the data, the mean and standard deviation of the levels of A $\beta-42$ after MCT administration. After the descriptive analysis, we do the comparative test. Because the data of this study were normally distributed and homogeneous, one way, ANOVA was used to see differences in the average of more than two groups. Then proceed to post hoc tests with bon-ferroni to see differences between groups.

\section{Results}

Data on levels of $A \beta-42$ in CSF rats were then processed with SPSS using the Annova and Bon Ferroni tests. The results showed that the K- group evince significantly lower levels of A $\beta$ 42 than rats in the $K+$ group. The average $A \beta-42$ level in the K-group was 27.30 while in the $\mathrm{K}+45.28$ group. The $\mathrm{K}+$ group showed a significant difference in $\mathrm{A} \beta-42$ levels in the MCT 1 and MCT 2 groups where the mean levels were 10.67 and 7.80 respectively. Between MCT 1 and MCT 2 there were no significant differences in the mean $A \beta-42$ results.

We can see from the data, the group of rats with MCT treatment had lower levels of A $\beta-42$ than the group of rats that were not given MCT. A $\beta-42$ levels on CSF describe beta-amyloid clearance in the brain, where if there is an imbalance in production and clearance, fragments of beta-amyloid will form oligomers which are toxic to brain neurons and the buildup of betaamyloid oligomers can develop into senile plaques which further worsens cognitive function 
disorders. The results showed that the maximum dose of MCT reduced levels of A $\beta-42$ greater than the minimum dose, but the difference was not significant.

Table 2. A $\beta-42$ levels in all groups

\begin{tabular}{llll}
\hline Groups & Minimum & Maximum & Average \\
\hline K - & 22.350 & 33.774 & 27.30 \\
K + & 36.773 & 52.961 & 45.28 \\
MCT 1 & 8.294 & 14.126 & 10.67 \\
MCT 2 & 3.774 & 13.108 & 7.80 \\
\hline
\end{tabular}

The data showed differences between the control group and MCT treatment group. But no significant difference between MCT with different dose.

Table 3. Comparative analysis of A $\beta-42$ levels after treatment of MCT intergroup

\begin{tabular}{lllll}
\hline Groups & & Mean difference & $\mathbf{p}$ & Interpretation \\
\hline $\mathrm{K}(-)$ & $\mathrm{K}(+)$ & 17,98 & 0,000 & \\
$\mathrm{~K}(+)$ & MCT 1 & 34,61 & 0,000 & $\mathrm{p}<0,05$ \\
& MCT 2 & 37,48 & 0,000 & \\
\multirow{2}{*}{ MCT 1} & $\mathrm{~K}+$ & 31,95 & 0,000 & \\
& $\mathrm{~K}-$ & 13,96 & 0,002 & $\mathrm{p}>0,05$ \\
& MCT 2 & 5,52 & 0,884 & \\
\hline
\end{tabular}

Between the negative control group and the positive control, it showed a significant difference in $A \beta-42$ levels, where the $A \beta-42$ level in the negative control group was lower than the positive control. However, the positive control group showed significantly higher levels of A $\beta-42$ than the treatment group. While the levels of $A \beta-42$ between the control groups did not show a significant difference.

\section{Discussion}

While the precise role of $A \beta$ in Alzheimer's Disease remains unresolved, it is clear that $A \beta$ serves as a pathological marker for the disease. Other physiologic changes may have reduced A $\beta$ levels in this study [13]. The ketone bodies from the MCT metabolism may have contributed as a glucose substitute for energy source metabolism. Besides, ketone bodies may serve as an efficient substrate for neuronal metabolism. Previous studies have shown that acute elevation of ketone bodies may improve cognitive performance in some individuals with Alzheimer's Disease [14].

While the precise role of $\mathrm{A} \beta$ in $\mathrm{AD}$ remains unresolved, it is clear that $\mathrm{A} \beta$ serves as a pathological marker for the disease. The development of $\mathrm{AD}$ and the accumulation of $\mathrm{A} \beta$ have been linked to dietary factors [13]. Dietary intervention for treating Alzheimer's disease relatively safe and available method against the progression of Alzheimer's Disease. Yet, how the mechanism of diet affects the pathological process of Alzheimer's is unclear [15].

While the effect of MCT treatment seems to be linked primarily to the production of ketones and their use an alternative energy source for the brain, the possibility of potential direct effects 
on MCT on brain metabolism has been raised recently [16]. In this study A $\beta-42$ was measured 1 time after treatment. Ideally, $\mathrm{A} \beta-42$ is measured before and after treatment. However, CSF retrieval in the rat cannot be carried out alive so that rats must be terminated before taking CSF. By looking at the many weaknesses in this study, further research is needed by looking at other parameters. However, it can be concluded that consumption of MCT can be hope as a solution to the elderly with Alzheimer's Disease, especially to prevent the deterioration. The results of this study provide a basis for further investigation of the effects of MCT on Alzheimer pathology, focusing on mechanisms that may be involved.

\section{References}

[1] Alzheimer's Association. Alzheimer's disease facts and figures. Alzheimer's Dement (2015).

[2] Duran GJ, Edna DM, Brisa E, et al. Amyloid $\beta$ modify the expression of antioxidant repair enzymes andapotassium channel in the septohippocampal system. Neurobiol Aging. pp. 20712076 (2013)

[3] Selkoe DJ: Alzheimer's disease: genes, proteins, and therapy. Physiol Rev 81:741-766 (2011)

[4] Zhao Y and Zhou B. Review Article : Oxidative Stress and The Pathogenesis of Alzheimers's Disease. Oxid Med Cell Longev (2013)

[5] Cunnane S, Nugent M, Roy M, Courchesne-Loyer A, Croteau E, Tremblay S, et al. Brain Fuel Metabolism, Aging and Alzheimer's Disease. Jnut 27 (1): 3-20 (2011)

[6] Costantini LC, Barr LJ, Vogel JL, Henderson ST. Hypometabolism as a therapeutic target in Alzheimer's disease. BMC Neurosci 9. pp.S16 (2008)

[7] Ward D and Jim E. Medium Chain Triglyserides : Beneficial Effects on Energy, Atherosclerosis and Aging. Nutr. Rev (2013).

[8] Carl ES and Jong M Rho. The Ketogenic Diet As a Treatment Paradigm For Diverse Neurological Disorders. Front Pharmacol 3:59 (2012)

[9] Fabian MD. Lauric Acid is a Medium-Chain Fatty Acid, Coconut Oil is a Medium-Chain Triglyceride. Phil Journal Sci. pp.157-166 (2014)

[10] Berit M, Maria P, Jurgen S. Review Medium-chain Triglyserides. Int Dairy J 16. pp. 1374-1382 (2016).

[11] Ngatijdan. Petunjuk Laboratorium, Metode Laboratorium dalam Toksikologi. Pusat Antar Universitas Bioteknologi Universitas Gajah Mada (2006).

[12] Kemas AH. Prinsip Percobaan dan Perancangannya. Rancangan Percobaan Aplikatif : Aplikasi Kondisional Bidang Pertanian, Peternakan, Perikanan, Industri dan Hayati. Edisi 1. Jakarta : PT Raja Grafindo Persada (2005)

[13] Auwera IV, Steefan W, Fred VL, Samuel TH. A ketogenic diet Reduce amyloid beta 40 and 42 in a mouse model of Alzheime's Disease. Nutr Metab. PP.2-28 (2005).

[14] Reger MA, Henderson ST, Hale C, Cholerton B, Baker LD, Watson GS, et al. Effects of betahydroxybutyrate on cognition in memory-impaired adults. NeurobiolAging. Pp. 311-314 (2004)

[15] Stokin GB, Lillo C, Falzone TL, Brusch RG, Rockenstein E, Mount SL, et al. Axonopathy and transport deficits early in the pathogenesis of Alzheimer's Disease. Science. pp. 1282-1288 (2005)

[16] Firoozeh N and Karen MM. Coconut oil attenuates the effects of Amyloid-Beta on cortical neurons in vivo. J Alzheimer Dis. pp. 233-237 (2014) 